\title{
CRÍTICA AO PASSADO, NOVA ESCRITA do futuro: CAROle PATEMAN, LUCE IRIGARAY E O PATRIARCALISMO ${ }^{1}$
}

Henrique Raskin (PUCRS) ${ }^{2}$

hraskin@hotmail.com

Resumo: Este artigo busca expor a sutileza da diferença entre o antigo e o novo, entre o arcaico e o moderno, a fim de questionar o caráter emancipatório da política na modernidade. A existência e a conjectura de um contrato sexual nas variadas formas da teoria do contrato social é o contexto no qual Carole Pateman desenvolve sua obra para expor a subversiva maneira com que as mulheres têm sido estimadas desde os primórdios da modernidade. $\mathrm{O}$ que é posto em questão, contudo, é o fato de que a crítica de Pateman, embora de maneira exitosa rejeite o contratualismo, por outro lado não supera a estrutura discursiva da própria tradição jusnaturalista. Tal insuficiência crítica motivará, a partir de Luce Irigaray, que se ponha à prova o próprio modelo falogocêntrico da filosofia e da psicanálise, os quais se reinscreverão quando as mulheres repensarem a história do pensamento sob uma normativa feminista.

Palavras-chave: Contratualismo; Modernidade; Psicanálise.

\section{INTRODUÇÃO}

Hera, a deusa grega do casamento, talvez fosse a melhor maneira de introduzir este artigo sobre feminismo. Estuprada e avergonhada por Zeus, não teve escolha senão casálo. E, punitivamente acorrentada, em fracassada insurreição

\footnotetext{
${ }^{1}$ Recebido em: 14-09-2017/ Aprovado em: 29-05-2018/ Publicado on-line em: 07-08-2018.

${ }^{2}$ Henrique Raskin é doutorando em Filosofia na Pontifícia Universidade Católica do Rio Grande do Sul, Porto Alegre, RS, Brasil.
} 
contra o marido, pôde ser liberta apenas sob a condição de obediência. A história de Hera, de fato, parece adequada para ilustrar uma opressão antiga e arcaica, colocada na forma do matrimônio. No entanto, ela aparece, já em seguida, como extremamente inoportuna para os fins deste texto, cujo objeto é a história do pensamento político moderno. Arcaico e moderno se chocam, por definição, como conceitos antagônicos e, por isso, não poderia um mito datado na antiguidade inaugurar um ensaio sobre a composição política na revolucionária e emancipatória modernidade.

O que procede é que, paradoxalmente, Hera permaneceu como a primeira palavra aqui escrita e, ademais, sua figura permeará todas as páginas seguintes deste texto. Adotando como axioma o livro 'The Sexual Contract', de Carole Pateman (1988), este artigo justamente buscará expor a sutileza da diferença entre o antigo e o novo, entre o arcaico e o moderno. $\mathrm{O}$ argumento de Carole Pateman é simples: a emancipação do patriarcalismo, que os modernos reivindicam, não teria acontecido; e a perpetuação de princípios pré-modernos, sob novas formas, teriam contaminado, desde o início, a modernidade, falsamente contraposta ao arcaico. Trazidos à luz, os elementos políticos da antiguidade e da Idade Média, ainda presentes na teoria política moderna, poderiam, então, implodir o empreendimento do contrato social, uma vez que jaz, no implícito e pressuposto contrato sexual, a refutação da superação moderna do patriarcado.

A existência e a conjectura de um contrato sexual nas variadas formas da teoria do contrato social é o contexto no qual Carole Pateman desenvolve sua obra para expor a sub- 
versiva maneira com que as mulheres têm sido estimadas desde os primórdios da modernidade. A partir de uma "negada e pressuposta liberdade das mulheres" (PATEMAN, 1988, pp. 231-232, tradução nossa), seu manifesto se opõe a um movimento filosófico cuja sustentação não seria possível de outra forma. É seguro afirmar que essa será a 'espinha dorsal' deste artigo, e certamente nos conduzirá através da discussão sobre o papel que a mulher teve, tem e poderá ter na modernidade, ainda que tardia. Porém, esse texto pretende ir além do constructo de Carole Pateman.

Os primeiros esforços do artigo se darão a desenvolver a deficiência da filosofia política moderna de incluir a (plena) liberdade da mulher: será demonstrado como a posição subserviente da mulher, já no estado de natureza de Hobbes, permanece nas noções do político em Locke e Rousseau. Após, serão abordadas duas formas contemporâneas de abordar o contrato social, que transformam e extinguem a abstração simplista e fictícia de um estado de natureza. Essas duas vias de recuperar e corrigir o contrato social aparecerão na forma da psicanálise concebida a partir de Freud e no neocontratualismo de Rawls. A importância, para nós, da consideração dessas duas formas de recuperação e correção do contratualismo, será, conforme Carole Pateman, para demonstrar que o problema da reprodução patriarcalista das relações entre homem e mulher não se esgotam na noção de estado de natureza, mas na própria concepção de um contrato social desenvolvido por pensadores homens.

Haverá, então, um movimento para além da obra de Carole Pateman, em relação ao contrato sexual - não como uma maneira de contrapô-la, mas em adição à sua tese. $\mathrm{Na}$ tentativa de rejeição de um modelo falogocêntrico da filoso- 
fia e da psicanálise, será questionado, a partir de Luce Irigaray, o que se reinscreverá quando as mulheres repensarem a história do pensamento sob uma normativa feminista. A solução para a incongruência entre contrato social e liberdade feminina, portanto, não poderia ser encontrada em uma perspectiva neocontratualista, tal como se adota em Rawls e em Freud. Deve-se problematizar o próprio papel da feminidade na construção de um pensamento, que, sobretudo, transborde e transgrida a importância da razão e do pênis.

\section{Modernidade E CONTRATUAlismo EM 'THE SEXUAL CONTRACT' DE CAROLE PATEMAN}

O 'cogito ergo sum' de Descartes já havia 'fundado' a modernidade, quando Hobbes falou em um contrato originário a inaugurar a sociedade civil. $O$ ceticismo cartesiano estabelecia a dúvida radical como a base epistemológica do rompimento com o passado e o movimento de Hobbes, neste quesito, não se propôs distinto. Não à toa que, frente ao teocentrismo medieval, a primeira parte do Leviatã já invoca em seu título 'Do Homem' o fundamento para suas conclusões (HOBBES, 1965, p. 11); porém, não é de graça que essa possa ter sido a mancha medieval a contaminar e a talvez refutar - a revolução que a política moderna poderia ter trazido. A teoria do contrato social de Hobbes teria sido estruturada a fim de rejeitar o legado patriarcalista da Bíblia, a partir do qual o poder político seria derivado de uma providência divina. Patriarcha or the natural power of kings, escrito por Filmer (1680), ainda que em resposta ao Leviatã (1651), sumariza veementemente a noção de que a figura do rei descendesse genealogicamente de Adão, o primeiro 
patriarca $^{\mathrm{i} 3}$. Poder político, para Filmer, seria análogo ao poder do pai, naturalmente justificado.

A questão colocada por Carole Pateman (1988) em 'The Sexual Contract' problematiza a ideia de que Hobbes, ao estabelecer o contrato social voluntário entre indivíduos livres e iguais, estivesse dissociado da tese paternalista de Filmer. O paternalismo arcaico de Filmer, ao contrário, não estaria ausente da essência do contrato empreendido pelos modernos; na realidade, um patriarcalismo hobbesiano, embora negado, estaria pressuposto já no estado de natureza que, supostamente, fornece os indivíduos livres e iguais para o firmamento do pacto político.

A crítica aponta para o caráter masculino da 'genérica' noção de indivíduo concebida por Hobbes, e o problema se dá justamente no fato de que, necessariamente, não poderiam ter sido incluídas as mulheres no momento do contrato social. O sujeito 'sem gênero', deve ser, logicamente, masculino no momento da fundação do pacto social, de uma maneira em que a guerra de todos contra todos do estado de natureza prepare o terreno para uma necessidade lógica no firmamento do contrato. Seguem as premissas em Hobbes, discutidas por Carole Pateman:

(1) "não há dominação natural no estado de natureza, nem mesmo de homens sobre mulheres; os atributos individuais não são respectivos a sexo" (PATEMAN, 1988, p. 44); assim, nenhuma dominação é predeterminada - qualquer um pode, a princípio, dominar qualquer outro.

\footnotetext{
${ }^{3}$ Cf. Filmer, 1680, p. 4: "we have an evident confession, that creation made man Prince of his posterity. And indeed not only Adam, but the succeeding Patriarchs had, by right of fatherhood, royal authority over their children".
} 
(2) as relações sexuais, portanto, dão-se ou sob consenso mútuo entre homem e mulher, ou a partir da sobreposição do homem à força perante a mulher - que, no entanto, pode retaliar e matá-lo;

(3) $\mathrm{Na}$ procriação, fruto das relações sexuais, apenas a mulher tem direito sobre o filho, uma vez que na criação, estabelece-se um pacto de submissão da criança em troca de proteção. Aparece aqui o único direito político do estado de natureza: o direito materno ${ }^{4}$.

Carole Pateman denuncia uma contradição lógica, uma vez que, em primeiro lugar, Hobbes enxerga, no estado de natureza, famílias como homólogas a reinos, unidos pela força (contrato). As sucessivas dominações em troca de proteção viriam a criar tribos, confederações, a partir das quais se estabeleceriam líderes, reis, dominantes a partir de contratos voluntários. E, em segundo lugar, o direito materno estabelece que a mãe, por direito logicamente constituído, obtém um papel de líder familiar análogo ao de líder do reino. Ela, naturalmente, ao parir, fornece proteção em troca de obediência aos filhos que naturalmente concordam com o acordo em troca de proteção e de criação. O problema da contradição aparece quando Hobbes afirma, no Leviatã ${ }^{5}$, que uma família "consiste em um homem e seus

\footnotetext{
${ }^{4}$ Pateman, 1988, p. 45. Cf. Hobbes, 1965, p. 154: "If there be no Contract, the Dominion is in the Mother. For in the condition of meer Nature, where there are no Matrimonial lawes, it cannot be known who is the Father, unlesse it be declared by the Mother: and therefore the right of Dominion over the Child dependeth on her will, and is consequently hers".

${ }^{5}$ Cf. Hobbes, 1965, p. 157: "By this it appears, that a great Family if it be not part of some Common-wealth, is of it self, as to the Rights Of Soveraignty, a little Monarchy; whether that Family consist of a man and his children; or of a man and his servants; or of a man, and his children, and servants together: wherein the Father or Master is the Soveraign".
} 
filhos; ou em um homem e seus servos; ou em um homem e seus filhos e seus servos juntos" (PATEMAN, 1988, p. 47). Duas alternativas surgem da antinomia: ao escrever 'homem', ou Hobbes comete um lapso improvável, buscando se referir a 'mulher' na liderança familiar análoga à liderança da soberania, brinca Carole Pateman, ou o filósofo assume que a superioridade do marido em relação à esposa (serva) é incluída e determinada na constituição do contrato social.

Eis a contradição: se a confederação entre indivíduos no estado de natureza se dá originalmente entre mãe e filho, e a partir de então cria-se uma analogia com a noção de reino, como as mulheres, livres, iguais e racionais, no contrato social, quereriam determinar-se elas próprias em uma posição inferior à do homem no casamento civil? A única explicação a esse problema lógico, conclui Carole Pateman, é a de que, sendo líderes naturais e tendo sido, posteriormente, submissas ao homem no contrato, todas as mulheres devem ter sido dominadas no estado de natureza, para que, na figura de servas, não tenham tido a liberdade necessária para o firmamento do pacto. Os senhores, que detêm a liberdade, são, então, todos homens no momento do contrato social. O indivíduo civil, assim, deve ser necessariamente homem, e a sujeição patriarcal não mais ocorrerá do homem sobre o filho, mas do homem sobre a mulher, a partir da inicial e fundamentadora luta de todos contra todos.

Ainda permanece sem explicação, em Hobbes, o motivo pelo qual as indivíduas mulheres - auto-interessadas por natureza - aceitariam a submissão de um infante em troca de proteção a ele. Isso apenas as prejudicaria em sua auto- 
conservação na anarquia do estado de natureza (PATEMAN, 1988, p. 49). Nesse aspecto, 'Two Treatises of Government' (1690), de Locke, parece corrigir a falha lógica de Hobbes, propondo um novo modelo ao estado de natureza, no qual a mulher não seja indivídua, deixando a liberdade e igualdade exclusivamente para os homens (PATEMAN, 1988, p. 52). Explicitamente posto, as mulheres se submetem ao homem no formato do casamento ainda no estado de natureza ${ }^{6}$, mas, em decorrência do acordo natural, a mulher detém, tal como o pai, o direito sobre os filhos ${ }^{7}$. Esse se mostra um ataque direto ao patriarcalismo de Filmer, que afirmava uma autoridade paterna sobre a prole; para Locke, diferentemente, a autoridade é parental, não paterna, e, por se tratar de um acordo pré-político, o casamento não necessariamente precisa ser mantido tal como um contrato de submissão eterna no mundo político ${ }^{8}$. Nesse sentido, Carole Pateman, junto a Zillah Eisens-

\footnotetext{
${ }^{6}$ Cf. Locke, 1823, §48 (Livro I): "If these words [when God says of Jacob and Esau, "that the elder should serve the younger"] here spoken to Eve must needs be understood as a law to bind her and all other women to subjection, it can be no other subjection than what every wife owes her husband; and then if this be the "original grant of government, and the foundation of monarchical power," there will be as many monarchs as there are husbands: if therefore these words give any power to Adam, it can be only a conjugal power, not political".

${ }^{7}$ Cf. Locke, 1823, 61 (Livro I): "The rule is, "Children, obey your parents;" and 1 do not remember, that I any where read, "Children, obey your father," and no more: the Scripture joins mother too in that homage which is due from children; and had there been any text, where the honour or obedience of children had been directed to the father alone, it is not likely that our author, who pretends to build all upon Scripture, would have omitted it: nay, the Scripture makes the authority of father and mother, in respect of those they have begot, so equal, that in some places it neglects even the priority of order, which is thought due to the father, and the mother is put first, as Lev. XIX. A".

${ }^{8}$ Pateman, 1988, p. 52. Locke, 1823, §48 (Livro I), complementa que o poder do marido, no entanto, é conjugal, e não político. Logo, o homem não possui sobre a mulher o poder político de vida ou morte sobre ela. Escreve: "the power that every husband hath to order the things of private concernment in his family, as proprietor of the goods and land there, and to have his will take place before that of his wife in all things of their common concernment; but not a political power of life and death over her, much less over any body else".
} 
tein', defenderá que Locke era um 'patriarcalista antipatriarcalista', ao opor-se enfaticamente ao modelo político de Filmer, no qual a paternidade de Adão derivava na primogenitura de sua descendência o poder político. Contudo, há um regresso em relação a Hobbes quando se contempla a natureza social em Locke, pelo motivo de que, novamente, tratar-se-ão como sinônimos "a gênese da família (patriarcal) [...] e a origem da vida social em si mesma [...], como um mesmo processo" (PATEMAN, 1988, p. 23, tradução nossa). É assim que o termo homem designa, literalmente para Locke, aos homens como indivíduos dotados de igualdade e liberdade no estado de natureza. Porém, ainda não se explica por que razão, na sociedade civil, aparece a entidade do casamento enquanto um contrato firmado entre iguais, uma vez que, por natureza, as mulheres já são sujeitas aos homens antes do contrato social. Carole Pateman coloca, dessa forma, que "o curioso recurso do casamento é que ele conserva o status natural ainda na sociedade civil. [... E] a primeira questão que deve ser perguntada é por quê o contrato é visto como o paradigma do livre acordo" (PATEMAN, 1988, p. 55, tradução nossa).

Rousseau, dentre os três contratualistas aqui analisados, talvez seja o pensador que mais explicitamente busque justi-

\footnotetext{
${ }^{9}$ Cf. Eisenstein, 1981, p. 33: "What we shall find is that Locke differentiates between family and political rule in order to free the market from paternalist, aristocratic relations, rather than to free the family from paternal rule. He recognized that the new relations of bourgeois society require a new definition of patriarchal rule to replace the equation of God, the father, and the king. The politics of the family and the politics of the state, he will conclude, are not one and the same thing. It will be a conclusion rooted in the actual historical changes of seventeenth-century England, as the home becomes distinguished from the market and the family from the state. This change will partially redefine the basis for the ideological distinction between the private and public worlds of male and female reality in particular liberal terms".
} 
ficar a submissão feminina à figura do marido no casamento, uma vez que, tal como Locke, Rousseau concebe a sociabilidade humana de forma natural ao homem. Especialmente por encontrar na família patriarcal o início da dependência humana, na transformação da vida animal natural à humana social, a submissão da mulher ao homem surge, quando, na relação humana, se desenvolvem as estruturas da razão e da linguagem ${ }^{10}$. Nessa revolução, a inferioridade moral surge na figura feminina (PATEMAN, 1988, p. 97). A passagem da natureza animal à sociedade humana não só cria a desigualdade entre os homens, mas determina, também a desigualdade entre homem e mulher ${ }^{11}$. Decorre

\footnotetext{
${ }^{10}$ Cf. Rousseau, 2002, p. 40: "On entrevoit un peu mieux ici comment l'usage de la parole s'établit ou se perfectionne insensiblement dans le sein de chaque famille, et l'on peut conjecturer encore comment diverses causes particulières purent étendre le langage, et en accélérer le progrès en le rendant plus nécessaire. De grandes inondations ou des tremblements de terre environnèrent d'eaux ou de récipices des cantons habités, des révolutions du globe détachèrent et coupèrent en îles des portions du continent. On conçoit qu'entre des hommes ainsi rapprochés et forcés de vivre ensemble, il dut se former un idiome commun plutôt qu'entre ceux qui erraient librement dans les forêts de la terre ferme”. A linguagem, no entanto, já sucede a diferenciação do trabalho doméstico, no que Rousseau, 2002, p. 39, previamente, escreve: "Chaque famille devint une petite société d'autant mieux unie que l'attachement réciproque et la liberté en étaient les seuls liens; et ce fut alors que s'établit la première différence dans la manière de vivre des deux sexes, qui jusqu'ici n'en avaient eu qu'une. Les femmes devinrent plus sédentaires et s'accoutumèrent à garder la cabane et les enfants, tandis que l'homme allait chercher la subsistance commune".

${ }^{11}$ Cf. Pateman, 1988, p. 97, tradução nossa: “'O físico', Rousseau discute em Emile, 'deixa a nós [mulheres] desconhecedoras da moral'. Aprendemos com base na consideração das diferenças físicas entre os sexos que a moralidade deles [homens] é também muito diferente. Mulheres, diferentemente dos homens, não podem controlar seus 'desejos ilimitados' sozinhas, de tal forma com que não possam desenvolver a moralidade requerida na sociedade civil”. Assim, escreve Rousseau, 1762, pp. 609-610, sobre a necessidade de merecer Sophie, devendo antes cumprir seus deveres perante seu país enquanto cidadão, para apenas depois poder tornar-se marido e pai: "Parlons de vous. En aspirant à l'état d'époux et de père, en avez-vous bien médité les devoirs? En devenant chef de famille, vous allez devenir membre de l'Etat. Et qu'est-ce qu'être membre de l'Etat? Le savez vous? Vous avez étudié vos devoirs d'homme, mais ceux de citoyen, les connaissez-vous? Savez-vous ce que c'est que gouvernement, lois, patrie? Savez-vous à quel prix il vous est permis de vivre, et pour qui vous devez mourir? Vous croyez avoir tout appris, et vous ne savez rien encore. Avant de prendre une place dans l'ordre civil, apprenez à le connaître et à savoir quel rang vous y convient. Émile, il faut quitter Sophie: je ne dis pas l'abandonner; si vous en étiez capable, elle Cont.
} 
dessa ideia que as mulheres aparecerão como subversivas à vida política, e a ordem social só poderá se manter com a contenção delas sob a forma da submissão conjugal ${ }^{12}$. Conclui Carole Pateman que "os homens devem ter seus próprios clubes sociais e políticos, a fim de educarem-se politicamente e fortalecerem sua cidadania, fora do alcance de mulheres e de suas influências subversivas e enfraquecedoras" (PATEMAN, 1988, p. 99, tradução nossa). Eis, então, a recuperação do conceito da fraternidade, normalmente ofuscado pelos valores da liberdade e da igualdade no brado da revolução liberal que foi a francesa. Fraternidade, não como universalidade, aparece enquanto irmandade masculina, acusa Carole Pateman; ou seja: o caráter da fraternidade não apenas devém contra a figura do patria potestas, o pai como figura da ordem política; mas o transforma, também, com a aniquilação da figura monocrática do 'rei pai', fazendo da sociedade civil uma irmandade

serait trop heureuse de ne vous avoir point épousé: il la faut quitter pour revenir digne d'elle. Ne soyez pas assez vain pour croire déjà la mériter. O combien il vous reste à faire! Venez remplir cette noble tâche; venez apprendre à supporter l'absence; venez gagner le prix de la fidélité, afin qu'à votre retour vous puissiez vous honorer de quelque chose auprès d'elle, et demander sa main, non comme une grâce, mais comme un recompense".

${ }^{12}$ Cf. Rousseau, 1762, p. 655, "Il faut, ma chère enfant, que je vous explique mes vues dans la conversation que nous eûmes tous trois avant-hier. Vous n'y avez peut- être aperçu qu'un art de ménager vos plaisirs pour les rendre durables. O Sophie! elle eut un autre objet plus digne de mes soins. En devenant votre époux, Émile est devenu votre chef; c'est à vous d'obéir, ainsi l'a voulu la nature. Quand la femme ressemble à Sophie, il est pourtant bon que l'homme soit conduit par elle; c'est encore la loi de la nature; et c'est pour vous rendre autant d'autorité sur son cœur que son sexe lui en donne sur votre personne, que je vous ai faite l'arbitre de ses plaisirs. Il vous en coûtera des privations pénibles; mais vous régnerez sur lui si vous savez régner sur vous; et ce qui s'est déjà passé me montre que cet art si difficile n'est pas au-dessus de votre courage. Vous régnerez longtemps par l'amour, si vous rendez vos faveurs rares et précieuses, si vous savez les faire valoir. Voulez-vous voir votre mari sans cesse à vos pieds, tenez-le toujours à quelque distance de votre personne. Mais, dans votre sévérité, mettez de la modestie, et non du caprice; qu'il vous voie réservée, et non pas fantasque; gardez qu'en ménageant son amour vous ne le fassiez douter du vôtre. Faites-vous chérir par vos faveurs et respecter par vos refus; qu'il honore la chasteté de sa femme sans avoir à se plaindre de sa froideur". 
de pais de família, a reger não o político, mas o privado (PATEMAN, 1988, p. 78).

No início de sua obra, o argumento de Carole Pateman que critica o movimento do contratualismo em seu caráter revolucionário e antipatriarcalista é fundamental para nós. Sustenta-se, a partir dos princípios tomados pelos filósofos do contrato social, sua repreensão da fundação do pensamento político moderno no que concernem as relações entre homem e mulher - seja no estado de natureza, seja na sociedade civil. O ponto é que, primordial ao contrato social - supostamente originário -, mostram-se presentes os pressupostos de um contrato sexual, não explícito, cujo conteúdo subjugaria, necessariamente, as mulheres ao poder patriarcal do homem. Não precisamente sob a ordem política do pai sobre o filho, tal como a Bíblia e Filmer viriam a pregar; mas no âmbito familiar, a partir do poder do homem no campo do não-político. O que deriva desse poder paterno em relação à família é, argumenta Carole $\mathrm{Pa}$ teman, o direito do homem ao corpo da mulher, sem o qual não pode haver a constituição familiar e, conseguintemente, não pode haver o poder paterno inerente ao homem (PATEMAN, 1988, p. 86). A constituição do espaço público na modernidade sustenta-se sobre a delimitação de um espaço privado; é essa a deixa para encontrar-se o argumento de que se mantém o patriarcalismo no contratualismo, pois pressupõe-se a dominação do homem sobre a mulher, na família, para que ele possa interagir com seus pares na artificialidade do político.

A questão que resta é se há uma correlação lógica e necessária entre a validade do modelo hipotético-dedutivo de um contrato social originário, e a tautologia da abstração 
com a realidade. Poderia a teoria do contratualismo, escrita por homens no princípio da modernidade, dar-nos um resultado diferente do que foi entregue? Ou mais: o patriarcalismo do contrato sexual implícito é inerente à noção moderna do contrato social? Carole Pateman não responde claramente, mas indica a direção em que segue. Ao invocar a psicanálise de Freud e o neocontratualismo de Rawls, a autora demonstra que a rejeição de um estado de natureza não corrige os pressupostos patriarcais dos modernos. A seção seguinte deste artigo exporá essas duas tendências contemporâneas de atualização da concepção moderna do contrato. No entanto, diferentemente do que foi feito até aqui, não nos contentaremos em apresentar, apenas, o argumento de Carole Pateman. Buscaremos transcender à discussão sobre o contrato, recuperando o papel da identidade humana e feminina nas relações sociais e políticas.

\section{UMA DISCUSSÃO CONTEMPORÂNEA PARA ALÉM DO CONTRATO SEXUAL}

Conforme colocado, o contratualismo moderno dos séculos XVII e XVIII apresentam deficiências ontológicas no estabelecimento de um estado de natureza. Primeiro, porque apresentam contradições lógicas no que concerne ao natural, pré-político, e ao contratual, político e, segundo, porque, assim, admitem tautologias que acusam o caráter ainda patriarcalista do momento histórico em que as teorias do contrato social foram desenvolvidas. Com a pretensão de superar o caráter fictício e obsoleto do contratualismo original, Carole Pateman aponta duas formas dominantes de neocontratualismo que, na contemporaneidade, remontam 
a lógica por trás do contrato social sem, no entanto, recorrer a abstrações históricas. Atentaremos, aqui, à psicanálise de Freud e ao liberalismo de Rawls, através da crítica apresentada em 'The Sexual Contract'. A intenção é a de demonstrar que, ainda que sem conceber um estado de natureza, os desdobramentos do contratualismo trazem consigo a dificuldade que a noção de indivíduo lógico engendra na superação de uma filosofia patriarcalista. Para isso, serão contrapostos os argumentos de Seyla Benhabib ao 'eu desimpedido' do individualismo e a proposta de Luce Irigaray de, na escrita feminista, romper-se a tradição histórica do falogocentrismo.

A atenção ao estudo psicanalítico encontra no complexo edipiano uma versão renovada do contrato social, a partir da gênese da 'civilização' europeia contemporânea a Freud. A tese original da psicanálise não reside a partir do construto de um estado de natureza, embora Freud tal qual Hobbes reconheça a natureza egoísta dos indivíduos; o que segue, todavia, é a transmutação da noção "da sociedade política como um artefato produto do medo" na "expressão da ânsia irracional do homem em restaurar a autoridade" (RIEFF, 1966, p. 223, tradução nossa). Autoridade do tabu, que, embora remonte às tribos denominadas primitivas, nas quais os totens simbolizam a linhagem familiar, diz respeito a uma "alegoria sobre o presente" (RIEFF, 1966, p. 225, tradução nossa), da realidade do neurótico, para o qual ainda existe a tensão necessária da autoridade em relação aos instintos. A existência do tabu, enquanto proibição severa, já indica "a inclinação do homem à anarquia" (RIEFF, 1966, p. 225, tradução nossa), mas o interesse de Freud especifica-se, conforme ele escreve em 'Totem und Tabu', a 
uma proibição "em quase todos os lugares em que encontramos totens" (FREUD, 1950, p. 7): a proibição do incesto.

A existência do tabu do incesto indica, portanto, a correspondência de uma inclinação natural ao cometimento desse ato tido como proibido. A manifestação do desejo de tal liberdade, no entanto, não aparece em Freud a partir de uma concepção hipotética de um estado de natureza, anterior ao estabelecimento da lei civil. Interessado pelo locus da subjetividade mediante as relações sociais, mais do que pelo estabelecimento de uma teoria política a justificar a ordem legal, é natural, então, que o objeto de estudo da psicanálise fosse o desenvolvimento dos afetos humanos desde o nascimento do indivíduo. $\mathrm{O}$ tabu do incesto nas diversas organizações sociais observadas daria, assim, o sentido pelo qual Freud viria a centralizar os impulsos da sexualidade já na vida do infante (RIEFF, 1966, pp. 224-225).

O complexo edipiano, assim, representará o momento em que convergem "os começos da religião, da moral, da sociedade e da arte" (FREUD, 1950, p. 99). Porém, não apenas no sentido histórico do 'começo', mas também no tempo lógico do sujeito que se desenvolve na civilização: o complexo edipiano "institui a consciência e cria o primeiro sentimento de culpa" (FREUD, 2011, p. 79). O filho, que 'mata' o pai a fim de satisfazer o desejo sexual pela mãe, deve ser castrado pela autoridade paterna e aceitá-la na lei da proibição do incesto. A ausência da intervenção paterna no desejo transgressor do filho pela figura materna, levaria à perversão da teoria freudiana.

$\bigcirc$ que nos interessa, em relação à tese psicanalítica do Édipo, é a referência interpretativa que Freud deve à teoria 
moderna do contrato social, conforme Rieff atesta. $\mathrm{O}$ princípio do complexo se dá no dia em que "os filhos se rebelam e matam o pai” (PATEMAN, 1988, p. 103, tradução nossa), tal como o contratualismo surgiu contra o patriarcalismo do poder político. A teoria do parricídio, porém, "não é seguida imediatamente pelo contrato original ou pela constituição da civilização. [...] A derrota do direito materno [...] sucede porque o ódio do filho em relação ao pai coexistia com a admiração de seu poder" (PATEMAN, 1988, p. 103, tradução nossa). Eis a narrativa da transformação do patriarcalismo político antigo no patriarcado privado moderno. O ponto é que por se instituir a 'lei do pai' apenas depois do parricídio, é na figura dos irmãos, livres da autoridade paterna, que a lei do pai, na fraternidade, toma a forma pública e imparcial (PATEMAN, 1988, p. 104). Carole Pateman questiona:

As histórias de Freud, tais como as de Sir Robert Filmer e dos contratualistas, começam com um pai que já é um pai. [...] Porém, um pai não pode tornar-se pai, a não ser que uma mulher se torne mãe, e ela não pode se tornar uma mãe sem o ato do coito. Onde está a história da verdadeira origem do direito político? (PATEMAN, 1988, pp. 104-105, tradução nossa).

A autora crítica ao contrato sexual coloca que Freud rejeita a ideia de que o parricídio não tenha sido um ato histórico na origem da humanidade. Ele admite que não se trata apenas de um impulso, em 'Totem und Tabu', uma vez que a imagem do coito entre o pai e a mãe da criança, ainda que consensual, pode representar ao filho um "ataque" do pai à mãe. No entanto, absolver o parricídio, significa logicamente, absolver, também, o estupro, ao considerar a violação do outro como motivo para o ato. Carole Pateman, 
contudo, aponta para a contradição de que, após o parricídio,

Nenhum dos irmãos poderá jamais ser o pai primordial, mas isso não os leva a renunciarem o direito patriarcal do sexo. Em vez disso, o direito se estende a todos os irmãos através da lei da exogamia. Ou seja: os irmãos fazem um contrato sexual. Estabelecem a lei que garante o acesso de cada homem a uma mulher (PATEMAN, 1988, p. 109, tradução nossa).

O falogocentrismo da teoria psicanalítica de Freud, cuja narrativa ocorre na relação pai-filho homem, estabelece que a criação do contrato de proibição do incesto tem a mulher como objeto, não como sujeito. Ela não participa da redação da lei, tal como o casamento tradicional significa a transferência da mulher do pai a outro homem, o marido. "Na competição sexual masculina, diferente da competição de mercado, todos os membros da fraternidade podem ganhar o prêmio" (PATEMAN, 1988, p. 114, tradução nossa). Para Freud, segundo Carole Pateman, esse é o contrato sexual que se replica todo dia a cada contrato matrimonial original realizado.

Um segundo modelo de renovação do contrato social na contemporaneidade é a proposta de Rawls de substituição da ficção política do estado de natureza pela adoção da posição original, enquanto construto racional, ideia da razão kantiana. Segue a seguinte lógica constitutiva ao projeto de Rawls em "A Theory of Justice":

(1) Tendo o contrato social como um acordo hipotético, os cidadãos de uma determinada democracia podem adentrar, através de um artifício da razão, na posição original, a fim de estabelecer um acordo sobre os princípios que regem as 
instituições políticas vigentes na sociedade;

(2) Na posição original, a noção de contrato social pode ser sempre revisada, desde que todos os participantes do acordo estejam vestidos sob o 'véu da ignorância', entidade capaz de fazer os indivíduos desconhecerem as particularidades que detêm no mundo concreto. Não se sabe, portanto, na posição original, se é-se mulher ou homem, o que instaura a igualdade entre as partes do contrato e permite que o ponto de vista de quem delibera politicamente seja aleatório e representativamente universal;

(3) Dada a ignorância da particularidade, não se pode inferir a partir do contrato social, então, que se estabeleça a submissão da mulher sob o homem, ou do homem sob a mulher, uma vez que as partes que determinam os princípios constitucionais não sabem se são homens ou mulheres. Não seria proveitoso, portanto, estabelecer princípios de desigualdade que possam prejudicar ao próprio interessado.

A crítica de Carole Pateman não contempla o modelo da posição original de Rawls em si, mas o fato de que o construto racional, em posição de total ignorância da particularidade, ainda assim postula que a deliberação política se dê com vistas à continuidade da linhagem de descendentes a seguirem os princípios determinados. Os representantes do contrato, então, são líderes familiares que procriam ou procriarão $^{13}$, e a pressuposição do coito ainda na posição

\footnotetext{
${ }^{13}$ Rawls, 1999, p. 111: "The question arises, however, whether the persons in the original position have obligations and duties to third parties, for example, to their immediate descendants. To say that they do would be one way of handling questions of justice between generations. However, the aim of justice as fairness is to try to derive all duties and obligations of justice from other reaCont.
} 
original permite inferir, para Carole Pateman, que os líderes familiares são sinônimos de homens que representam suas esposas (PATEMAN, 1988, p. 43). É injusta a afirmação, especialmente quando o conceito de líder familiar utilizado por Rawls é formal, sem contemplar a particularidade do sexo ou gênero. O que Rawls pretende é estabelecer a capacidade de se desenvolver na posição original uma teoria da justiça, que se sustente perante as futuras gerações. Porém, é possível compreender a crítica da autora, que tem na leitura da tradição liberal o contrato sexual como pré-político. Assim, fora da posição original, prevê-se naturalmente a constituição familiar, como apolítica, já sendo pressuposta no momento do consenso sobreposto ${ }^{14}$. O problema será demonstrar que Rawls determina o homem como necessariamente o líder familiar.

Isso não esgota, contudo, a crítica feminista que pode ser e é feita à filosofia política de Rawls. Seyla Benhabib e Drucilla Cornell, opondo-se à racionalidade liberal rawlsiana, condenam o "eu desimpedido", o "sujeito descompromissado", tão rejeitados por noções comunitaristas da

\footnotetext{
sonable conditions. So, if possible, this way out should be avoided. There are several other courses open to us. We can adopt a motivation assumption and think of the parties as representing a continuing line of claims. For example, we can assume that they are heads of families and therefore have a desire to further the well-being of at least their more immediate descendants. Or we can require the parties to agree to principles subject to the constraint that they wish all preceding generations to have followed the very same principles. By an appropriate combination of such stipulations, I believe that the whole chain of generations can be tied together and principles agreed to that suitably take into account the interests of each $(\$ \S 24,44)$. If this is right, we will have succeeded in deriving duties to other generations from reasonable conditions".

${ }^{14}$ Pateman, 1988, p. 43: Rawls' original position is a logical abstraction of such rigour that nothing happens there. In contrast, the various states 'of nature pictured by the classic social contract theorists are full of portray the state of nature as a condition that extends over more than one generation. Men and women come together; engage in sexual relations and women give birth. The circumstances under which they do so, whether conjugal relations exist and whether families are formed, depends on the extent to which the state of nature is portrayed as a social condition.
} 
constituição individual. Isso porque ao adotar a concepção atomística do indivíduo liberal, para a crítica feminista, significa acatar os pressupostos da independência e do isolamento que jamais na história caracterizaram a existência da mulher, sempre "membro de uma família, como irmã de alguém, esposa de alguém e mãe de alguém" (BENHABIB et CORNELL, 1987, p. 19). O feminismo, de acordo com Seyla Benhabib e Drucilla Cornell, deve partir de um 'eu situado' - não de um 'eu' artificialmente racional, conforme defende Rawls; é a renegociação das identidades psicossexuais e a reconstituição da noção de indivíduo que devem permanecer como centralidade do discurso político filosófico (BENHABIB et CORNELL, 1987, p. 19).

Em "Situating the Self", Seyla Benhabib não apenas se contrapõe a Rawls, mas ao modelo de espaço público como distinto ao privado, o lugar comum do liberalismo. Sua crítica se sustenta em três argumentos. Primeiro, que o modelo do indivíduo racional da posição original não pode conduzir à discussão política acerca de alguma particularidade. Apenas pautas universais que concirnam à forma vazia de indivíduo podem ser discutidas; ela, assim, questiona por que motivo questões morais não poderiam ser reivindicadas com pretensões à universalidade, mesmo partindo de uma constituição particular do indivíduo. Em segundo lugar, na linha tênue de separação entre o bem e o justo, há a presunção de uma neutralidade moral: a noção vazia de 'parte negociante' da posição original encaminharia o leitor em direção a essa falsidade. Para Seyla Benhabib, sempre haverá a sobreposição de uma concepção de bem sobre a outra; então que, ao menos, possa se permitir a oportunidade de manifesto de todas as concepções de bem. E, em 
terceiro lugar, o fato de os indivíduos terem de simular a ignorância de suas concepções de bem, despirem-se de seus valores morais, para que pensem a estrutura política, é opressivo por si só (BENHABIB, 1992, p. 167). Seyla Benhabib, a partir de sua crítica, não quer pensar como indivíduo, quer pensar como mulher. Se não o fizer, estará pensando como homem.

Análoga a essa reconstrução do papel da mulher enquanto agente político, é a própria reconstituição psicanalítica da teoria falogocêntrica do Édipo. O que permeia o debate é que entra em jogo, além da causa feminista por si só, um problema que concerne a epistemologia, a partir da relação entre ser e pensar. $\bigcirc$ que se está discutindo, nas entrelinhas, é se as duas categorias da existência são antagônicas entre si ou se, inexoravelmente, imbricam-se uma na outra. Ser mulher é pensar mulher? Se a resposta for não, a crítica de Carole Pateman não deverá mais se direcionar ao contrato social em si, mas às condições sobre as quais ele pode estar sendo sustentado. Mas, se a resposta for sim, o cogito ergo sum de Descartes deverá ser invertido, junto com a modernidade. 'Existo, logo penso' será, então, o fundamento de uma nova teoria social da humanidade, a partir, também, de um pensar mulher, escrito por mulheres.

É possível indagar se a associação ou dissociação entre ser e pensar é o divisor de águas entre um feminismo psicanalítico preocupado mais com as relações políticas, e um feminismo psicanalítico voltado à linguagem e ao discurso. Tal seja, possivelmente, a distinção que Cossi percebe no feminismo da segunda onda entre uma escola anglo-saxã, "sustentada pela teoria das relações de objeto" (COSSI, 2017, p. 11) e a escola francesa, em que se "pregava predo- 
minantemente a atuação na linguagem e $O$ (re)posicionamento da mulher no discurso" (COSSI, 2017, p. 11). Nesta distinção, pode-se, quem sabe, explicar por que a inglesa Carole Pateman assume uma postura crítica contra o contrato sócio-sexual sem, no entanto, transcender à própria estrutura discursiva da teoria política. Ela conclui seu livro, em decorrência disso, afirmando que havia completado o tema da obra sem, no entanto, finalizá-lo ${ }^{15}$. A questão é se Carole Pateman, embora tenha exposto e condenado o contratualismo em seu patriarcalismo, poderia, a partir de suas ferramentas aplicadas, finalizar o assunto.

Carole Pateman utiliza a razão política para explicar o falocentrismo de Freud; porém, o princípio de uma revolução epistêmica só poderia residir na reconstrução da psicanálise como o fundamento de implosão do logos. A conciliação no termo do falogocentrismo junta a forma e o conteúdo de forma indissociável, e é por isso que a iniciativa da "escrita feminina" francesa dá um passo além da mera condenação. $O$ conteúdo da forma dos frequentes 'jeux de mots', é propriamente a afronta de Luce Irigaray à estrutura da linguagem que preconiza o logos e o falo. Não por acaso, em 'Speculum de l'autre femme', a caverna da alegoria de Platão assume o cenário do parto contraintuitivo do homem em direção à luz da razão.

Algum instigador, algum obstetra-acólito, algum corte sem rosto, sem nome, do qual sabemos apenas ser macho, irá com a mão firme

\footnotetext{
${ }^{15}$ Cf. Pateman, 1988, p. 233-234: "Baudelaire once wrote that 'there is a world of difference between a 'completed' subject and a 'finished' subject and that in general what is 'completed' is not 'finished'. I have completed what I have to say about the sexual contract, but the story is far from finished. The political theory is still showing vital signs and political theory is insufficient to undermine the life-supports".
} 
forçosamente extrair o filho-prisioneiro, contra sua vontade, de seu lar anterior. Irá arrancá-lo da cova, forçando-o, através do caminho rochoso cheio de obstáculos que podem rasgar e mutilar sua carne, em direção da encosta íngreme, do eixo vertical, da luz do dia, fora do lugar onde ele sempre morou. Arrastando-o, irá afastá-lo da câmara subterrânea, sua fortaleza, a fim de levá-lo à vista do Sol, a partir de um domínio autoritário e rígido durante a escalada selvagem. Então, o homem vigorosamente arrastado estará (provavelmente) satisfeito, mas preenchido por sofrimento e indignação. Alguém, em suma, irá (provavelmente) agir de tal forma a trazer o pobre coitado (de volta) aos caminhos da razão. O que essa tal forma significa? (IRIGARAY, 1985, pp. 278-279, tradução nossa).

Luce Irigaray traça, na descrição, um paralelo entre a saída do homem da caverna de Platão ao parto, no qual a criança é retirada do útero contra o seu conforto. A tese da natureza da busca pela Verdade, pela razão é, portanto, problematizada pela proposta de um retorno ao útero da mãe. Por que passar do acolhedor colo materno ao falo rígido da razão paterna? (IRIGARAY, 1985). Poderíamos, com a negação do falo e do logos, reconstituir uma nova escrita normativa para um novo locus da mulher na história e, então, na política? Tal como o encontro da razão no exterior da caverna mostrara a dura opressão da realidade fálica, a emancipação reivindicada pela modernidade empurrou a mulher, não só nas entrelinhas, para o interior do privado.

A questão de Luce Irigaray é problemática, quando, antes da saída do homem da caverna, a deusa do casamento Hera já tivesse sido estuprada e transformada em esposa de Zeus. No entanto, é tão válida quanto a denúncia de Carole Pateman, que viu na liberdade moderna um tão grande confinamento. Volta-se então, ao começo. Poderia a história do pensamento, moderno ou arcaico, tal como ela se deu, ter sido escrita por mulheres? Ou, se tivesse sido escrita 
pelos lábios vaginais, separados e calados pelo pênis, a política seria hoje diferente? Retrospectivamente, não podemos voltar à caverna e nos despir do logos coagido. Porém, não estamos fadados a reproduzi-lo: é na recomposição da voz feminina, na contraposição ao falo, e na sororidade, como alternativa à maternidade, que a morte do pai será a morte da mãe.

\section{CONSIDERAÇÕES FINAIS}

Tendo deslocado o argumento deste artigo a partir da crítica de Carole Pateman em direção à 'escrita feminina' de Luce Irigaray, significa que deve ser considerada a importância normativa de uma nova formulação teórica acerca da política, da história, ou da própria existência humana. Partindo-se de Hobbes, Filmer, Locke, Rousseau, Freud e Rawls, deve-se perguntar se não resta aí a própria justificativa de estarmos discutindo o pertencimento da mulher à esfera reprodutora do privado. Como poderia Freud, por exemplo, não ter feito do clitóris um pequeno pênis, se seu referencial linguístico e teórico advinha de uma tradição escrita e pensada por homens? O problema urge, portanto, à inclusão de mulheres na reconstrução da história e na construção do futuro do pensamento. Carole Pateman, por um lado, reconstrói, ao negativamente criticar e apontar para os lapsos e intenções patriarcalistas de uma modernidade que se diz livre de pressupostos; Luce Irigaray, em contrapartida, advoga por uma nova escrita, uma linguagem com gramática e semântica próprias, que venha a resgatar a humanidade do unilateralismo falogocêntrico.

Isso significa, então, que na calada dos homens que es- 
creveram a história, devam calar-se todos os homens ainda a escrever o futuro? Ou existe lugar para a pluralidade, inclusive, dos sexos? Essa é uma questão que suscita divergência, e que não poderá ser resolvida aqui. No entanto, podemos invocar algumas conclusões acerca do que foi escrito neste texto, por um homem.

(1) Censurar é oprimir, da mesma forma com que vestir o véu da ignorância é reprimir a si mesmo. A crítica feminista de Seyla Benhabib justamente condena a noção liberal em Rawls, de uma posição original, por obrigar a mulher a não pensar como mulher no momento da deliberação. Isso, para Rawls, significaria pensar de forma neutra, apesar de a crítica comunitarista defender que, nesse caso, pensar neutro é pensar como um homem da tradição liberal.

(2) A ação de calar a escrita masculina, ainda que patriarcalista, não transgride a lógica falogocêntrica de reconhecer no logos, no falo, no singular, a Verdade com letra maiúscula. A duplicidade dos lábios desenhados por Irigaray permite, inclusive, entender a posição secundária do feminino perante o masculino. A reação, assim, é contida não no uno platônico, mas na afirmação do múltiplo.

(3) Podemos, com isso, caminhar em direção ao silenciamento não do homem, mas de uma filosofia dominante que, em sua unicidade, cala as demais. Mesmo que ser homem necessariamente signifique pensar homem, a revolução se dará nas mulheres a escrever de maneira mulher, em contrapartida. Não precisa ser necessário calar, mas contrapor em mesma intensidade. 
Dessa forma, não concluímos a discussão apresentada nesse artigo. Pelo contrário, nos resta deixar para a história mostrar a contingência que somente a pluralidade pode produzir. Eis a verdadeira liberdade, palavra feminina.

Abstract: This paper seeks to expose the subtlety of the difference between the old and the new, between the archaic and the modern, in order to question the emancipatory character of modern politics. The existence and the conjecture of a sexual contract in the various forms of social contract theory is the context where Carole Pateman develops her work to expose the subversive way women have been estimated since early modernity. What is questioned, however, is the fact that Pateman's critic, even though successfully rejecting contract theory, does not overcome the discursive structure of natural law tradition. Such critical insufficiency will motivate, from Luce Irigaray, that one puts to the test the phallogocentric model of philosophy and psychoanalysis itself, which will rewrite themselves when women rethink the history of thought through a feminist normativity.

Keywords: Contract theory; Modernity; Psychoanalysis.

\section{REFERÊNCIAS}

BENHABIB, Seyla; CORNELL, Drucilla. 'Além da Política do Gênero'. In: BENHABIB, Seyla; CORNELL, Drucilla (org.). Feminismo como Crítica da Modernidade. Rosa dos Tempos: Rio de Janeiro, 1987.

. Situating the Self: gender, community and postmodernism in contemporary ethics. Routledge: New York: 1992.

COSSI, Rafael K. 'Apresentação à edição brasileira'. In: IRIGARAY, Luce. Este Sexo que não é só um sexo. Senac: São Paulo, 2017.

EISENSTEIN, Zillah. The Radical Future of Liberal Feminism. Longman: New York, 1981. 
FILMER, Robert. Patriarcha. 1680. Disponível em:

$<$ http://pages.uoregon.edu/dluebke/301ModernEurope/Fil merPatriarcha1680.pdf $>$.

FREUD, Sigmund. Totem e Tabu. 1950. Disponível em:

$<$ http://www.planonacionaldeleitura.gov.pt/clubedeleituras /upload/e_livros/clle000164.pdf>.

. O mal-estar na civilização. Companhia das Letras: São Paulo, 2011.

HOBBES, Thomas. Leviathan. The Clarendon Press: Oxford, 1965. Disponível em: 〈http://files.libertyfund.org/files/869/0161_Bk.pdf>.

IRIGARAY, Luce. Speculum of the Other Woman. Cornell University Press: Ithaca, 1985.

LOCKE, John. Two Treatises of Government. McMaster University Archive: London, 1823. Disponível em: $<$ http://socserv2.socsci.mcmaster.ca/econ/ugcm/3113/locke /government.pdf $>$.

PATEMAN, Carole. The Sexual Contract. Stanford University Press: Stanford, 1988.

RAWLS, John. A Theory of Justice. Harvard University Press: Cambridge, 1999. Disponível em: http://www.univpgri-palembang.ac.id/perpusfkip/Perpustakaan/American\%20Phylosophy/John\%20Ra wls\%20\%20A\%20Theory\%20of\%20Justice \%20Revised $\% 20$ Edition.pdf $>$.

RIEFF, Phillip. Freud: la mente de um moralista. Editorial 
Paidós: Buenos Aires, 1966.

ROUSSEAU, Jean-Jacques. Émile, ou De l'educación. 1762. Disponível em: <http://philovelo.free.fr/Textes-dephi-

lo/Les_oeuvres_completes/Rousseau_Emile_ou_de_1_edu cation.pdf>.

- Discours sur l'origine et les fondements de l'inegalité parmi les hommes. 2002. Disponível em: $<$ http://eet.pixelonline.org/files/etranslation/original/Rouss eau\%20JJ\%20Discours\%20sur.pdf $>$. 